\title{
Controle de Macroptilium lathyroides com herbicidas aplicados em pré e pós- emergência ${ }^{1}$
}

\author{
Macroptilium lathyroides control with pre and post-emergence herbicide \\ applications
}

\begin{abstract}
Germani Concenco ${ }^{2 *}$, André Andres ${ }^{3}$, Leandro Galon ${ }^{4}$, Cristiano Silva Pontes ${ }^{5}$, Vinicius Talhari Correia $^{5}$
\end{abstract}

Resumo - A espécie Macroptilium lathyroides (feijão-de-rôla) foi encontrada infestando áreas relativamente extensas de cultivo de soja na região Sul do Mato Grosso do Sul, onde produtores se queixaram da falta de eficiência de controle de herbicidas. Não existe nenhum herbicida registrado para o controle da espécie, e o número de pesquisas envolvendo a suscetibilidade a diversos princípios ativos é limitado. Objetivou-se com este estudo verificar a eficiência do herbicida glyphosate, isolado ou em associação a outros princípios ativos, no controle de $M$. lathyroides em três estádios de desenvolvimento, bem como encontrar outras alternativas de controle químico para utilização em pré e pós-emergência. O estudo foi instalado em casa de vegetação, constituindo-se do estabelecimento das plantas em vasos plásticos com $4 \mathrm{dm}^{3}$ de solo, onde herbicidas foram aplicados, conforme tratamentos, em três momentos: pré-emergência (4 dias após semeadura), pós-emergência inicial (4 a 6 folhas definitivas) e pós-emergência tardia (início do florescimento). Em pré-emergência, o M. lathyroides mostrou-se suscetível ao sulfentrazone e ao diuron; em pós-emergência inicial, glyphosate e trifloxysulfurom-sodium foram eficientes, e em pós-emergência tardia o glyphosate e o amonio-glufosinate também proporcionaram controle eficiente. A eficiência do carfentrazone-ethyl foi dependente do estádio de desenvolvimento da espécie e o pyrithiobac-sodium não demonstrou controle satisfatório. Novas avaliações devem ser conduzidas em condições de campo para confirmar os resultados obtidos neste estudo em ambiente controlado.

Palavras chaves: feijão-de-pomba; feijão-dos-arrozais; controle químico.

Abstract - Macroptilium lathyroides (wild bushbean) specie was found infesting relatively large areas of soybeans in the southern region of Mato Grosso do Sul State, Brazil, where farmers

\footnotetext{
* Autor para correspondência

${ }^{1}$ Recebido para publicação em 14/11/2011 e aceito 26/03/2012.

2 Eng. Agrônomo, D.Sc. em Fitotecnia, pesquisador da área de herbologia da Embrapa Agropecuária Oeste, Dourados-MS, germani@cpao.embrapa.br;

${ }^{3}$ Eng. Agrônomo. M.Sc. em Fitotecnia, pesquisador da área de herbologia da Embrapa Clima Temperado, PelotasRS, doutorando no Dipartimento di Agronomia, Selvicoltura e Gestione del Territorio, Università di Torino, Grugliasco-TO, Italia.

${ }^{4}$ Eng. Agrônomo, D.Sc. em Fitotecnia, professor da Universidade Federal da Fronteira Sul (UFFS), Campus Erechim-RS;

${ }^{5}$ Estudante de Agronomia, estagiário da área de herbologia da Embrapa Agropecuária Oeste, Dourados-MS;
} 
complained about lack of herbicides efficiency in controlling this species. There is no herbicide registered for controlling this species in Brazil, and the amount of researches involving its susceptibility to several actives principles is so limited. This study aimed to verify the efficiency of glyphosate herbicide, isolated or in association with other actives principles, in controlling $M$. lathyroides at three crop growth stages, as well as to find alternative herbicides for chemical control of this species in pre- and post-emergence. The experiment was conducted under greenhouse conditions, where plants were established in plastic vases containing $4 \mathrm{dm}^{3}$ of soil, where herbicides were applied, according to the treatments, in three moments: pre-emergence (4 days after seeded), early post-emergence (4 to 6 definitive leaves) and late post-emergence (initial flowering). Under pre-emergence applications $M$. lathyroides was particularly susceptible to sulfentrazone and diuron herbicides; in early post-emergence, glyphosate and trifloxysulfuronsodium were efficient, and in late post-emergence glyphosate and ammonium-gluphosinate were also efficient in controlling this species. Carfentrazone-ethyl efficiency was dependent on growth stage and pyrithiobac-sodium did not show satisfactory control. Further studies must be conducted under field conditions to confirm the results obtained in this study under controlled environment.

Key words: wild pea bean; wild bushbean; chemical control.

\section{Introdução}

A subtribo Phaseolinae Benth. (Leguminosae) compreende 21 gêneros e cerca de 315 espécies, com distribuição pantropical. Suas espécies são caracterizadas principalmente pelo hábito volúvel, folhas trifolioladas e estilete barbado. Muitas espécies apresentam potencial econômico, e por este motivo são amplamente difundidas e cultivadas por todo o mundo (Snak, 2011). O Gênero Macroptilium engloba aproximadamente 20 espécies, sendo um dos Gêneros mais conhecidos na subtribo Phaseolinae (Delgado-Salinas \& Lewis, 2008). Recentemente, uma espécie muito rara deste gênero, Macroptilium cochleatum, foi descoberta no Brasil (Delgado-Salinas \& Lewis, 2008). Segundo estes autores, esta espécie havia sido identificada pela última vez há 150 anos.

Dentre as espécies com uso econômico, se destacam $M$. atropurpureum (siratro), e $M$. lathyroides que são utilizadas como plantas forrageiras (Monks et al., 2006; Guerra et al., 2007; Vasconcelos et al., 2011).
M. lathyroides é conhecido por diferentes nomes: figo-de-pombo (Vasconcelos et al., 2011), feijão-dos-arrozais (Ferreira et al., 2004) ou feijão-de-rôla (Basile et al., 2007) são as sinonímias mais comuns. O feijão-derôla, particularmente, apresenta características apropriadas para solos úmidos, podendo alcançar altos rendimentos de forragem de qualidade. Pouco exigente em fertilidade, vegeta em locais mal drenados e com $\mathrm{pH}$ baixo, além de ser adaptada a precipitações pluviais anuais de 630 a $1800 \mathrm{~mm}$ ou mais (Monks et al., 2006; Vasconcelos et al., 2011).

Devido às características de adaptabilidade a diferentes ambientes e ao curto ciclo reprodutivo com facilidade de produção de sementes, estas espécies podem se tornar plantas daninhas em cultivos onde o sistema de manejo favoreça seu desenvolvimento. No Estado do Mato Grosso do Sul (MS), foram encontradas áreas de cultivo de algodão e de soja com alta infestação de siratro e de feijão-de-rôla. Siratro foi constatado infestando áreas de algodão relativamente extensas na região Norte do Estado (região do Município de Chapadão do 
Sul), e feijão-de-rôla infestando área de soja na região Sul do Estado.

Atualmente não existem herbicidas registrados para o controle químico destas espécies, o que impossibilita a recomendação. Além disso, são reduzidos os resultados de pesquisa envolvendo a eficiência de herbicidas sobre espécies de Macroptilium spp. Santos et al. (2000) ressaltaram que oxadiazon é eficiente no controle de feijão-de-rôla no cultivo do arroz. Basile et al. (2007) também obtiveram satisfatória eficiência de controle de plantas adultas desta espécie com o herbicida glyphosate, embora vários produtores das regiões onde estas espécies ocorrem no Mato Grosso do Sul tenham se queixado de falta de eficiência deste herbicida sobre siratro e feijão-de-rôla.

Neste estudo objetivou-se verificar a eficiência do herbicida glyphosate, isolado ou em associação a outros princípios ativos, no controle de $M$. lathyroides em três estádios de desenvolvimento, bem como encontrar outras alternativas de controle químico para utilização em pré e pós-emergência.

\section{Material e Métodos}

O experimento foi conduzido em casa de vegetação na Embrapa Agropecuária Oeste, Município de Dourados, Estado de Mato Grosso do Sul, entre abril e agosto de 2011. As sementes de $M$. lathyroides (feijão-de-rôla) foram oriundas de propriedades no distrito de Itahum, Dourados-MS, distante cerca de 100 $\mathrm{km}$ desta cidade. As sementes de feijão-de-rôla foram coletadas em lavoura cultivada com soja resistente a glyphosate nos últimos cinco anos, onde desde a safra 2009-2010, observou-se o baixo nível de controle desta espécie com o herbicida glyphosate.

As vagens desta espécie se desidratam ao atingirem a maturação e se rompem, lançando as sementes a distâncias consideráveis. Assim, as vagens foram colhidas quando maduras, porém um pouco antes do estádio de rompimento espontâneo. As mesmas foram acondicionadas no interior de sacos de papel para desidratar em casa de vegetação, de forma que as sementes fossem retidas no pacote. Após o rompimento espontâneo das vagens, as sementes foram separadas das demais impurezas e escarificadas com lixa, conforme recomendação de Almeida et al. (1979) para sementes de siratro ( $M$. atropurpureum), devido a falta de recomendação específica para feijão-de-rola. A semeadura foi realizada ao redor de 30 dias após a coleta das vagens no campo.

Três experimentos foram instalados em casa de vegetação, em delineamento experimental completamente casualizado com quatro repetições. $\mathrm{O}$ primeiro experimento constou dos tratamentos aplicados em préemergência; o segundo dos tratamentos aplicados em pós-emergência inicial e o terceiro dos herbicidas aplicados em pósemergência tardia, sendo analisados em conjunto após verificação de homogeneidade de variâncias e compatibilidade dos coeficientes de variação. As unidades experimentais foram compostas por vasos plásticos com $4 \mathrm{dm}^{3}$ de solo, preenchidos com solo peneirado e adubado conforme recomendações para a cultura da soja. O solo das unidades experimentais foi irrigado previamente a semeadura de vinte sementes, que foram distribuídas na superfície do solo em cada unidade experimental. As sementes foram cobertas com camada de $4-8 \mathrm{~mm}$ de areia fina. Aos 7 e 14 dias após a emergência (DAE) foi realizado desbaste somente nos baldes destinados aos tratamentos em pósemergência, mantendo sete plantas por unidade experimental. Nos tratamentos com aplicação em pré-emergência, o número de plantas emergidas por parcela se constituiu em uma das variáveis avaliadas. As parcelas 
foram mantidas úmidas durante toda a duração do experimento, sendo irrigadas duas vezes ao dia. Aos 14 DAE foi aplicada $180 \mathrm{~kg} \mathrm{ha}^{-1} \mathrm{de}$ nitrogênio como forma de estimular o lento crescimento das plantas em função das baixas temperaturas predominantes no período do experimento.

Para cada grupo de tratamentos (PRÉ, PÓS-I, PÓS-T) foi mantido um tratamento testemunha específico (Tabela 1). Os herbicidas foram aplicados nas primeiras horas da manhã com pulverizador costal propelido a $\mathrm{CO}_{2}$, munido de barra com uma ponta Teejet DG 110.015, com pressão constante e volume

Tabela 1. Herbicidas, dosagens, épocas de aplicação e estádio de desenvolvimento do Macroptilium latyroides por ocasião da aplicação dos tratamentos. Embrapa Agropecuária Oeste, Dourados-MS, 2011.

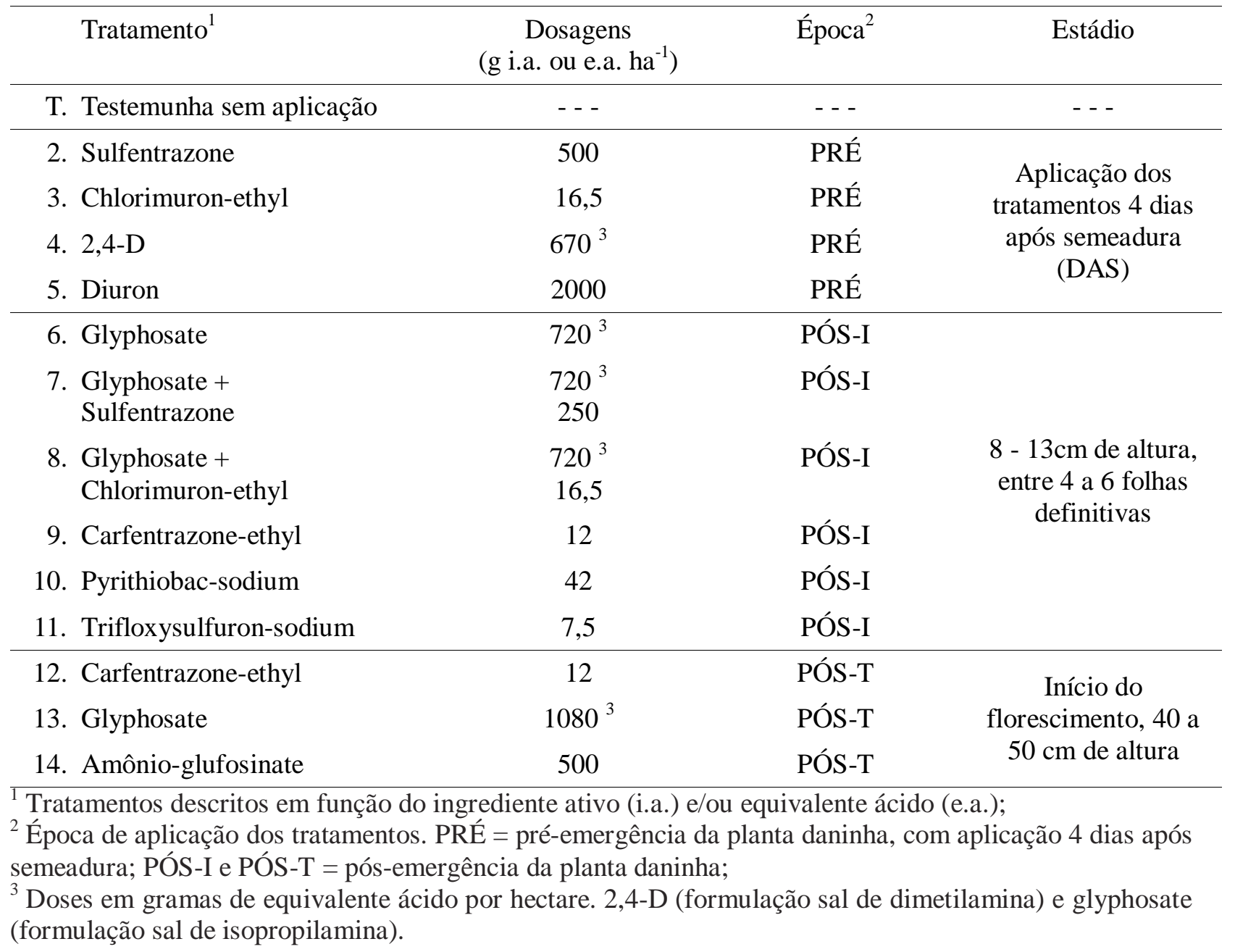

Rev. Bras. Herb., v.11, n.1, p.11-23, jan./abr. 2012

de calda de $140 \mathrm{~L} \mathrm{ha}^{-1}$. No momento das aplicações, as condições ambientais eram propícias à aplicação, caracterizada por velocidade dos ventos entre 2 e $8 \mathrm{~km} \mathrm{~h}^{-1}$, temperatura entre 22 e $27{ }^{\circ} \mathrm{C}$ e umidade relativa do ar acima de $65 \%$. No momento da aplicação o solo encontrava-se em capacidade de campo. Após a aplicação dos herbicidas, as plantas permaneceram ao externo da casa de vegetação por 20 minutos para secagem completa da calda de pulverização, quando então foram devolvidas aos seus locais originais no delineamento experimental. (1) 
As avaliações de eficiência de controle foram realizadas aos 7, 14, 21, 28 e 42 dias após a aplicação dos herbicidas (DAA) para os tratamentos em pré-emergência, e aos 7, 14, 21 e 28 DAA para os tratamentos em pós-emergência inicial e tardia. Para a avaliação foi utilizada uma escala baseada em parâmetros visuais, de acordo com o European Weed Research Council (1964), com valores variando entre zero e 100, onde zero representou ausência total de sintomas nas plantas, e 100 a morte total das plantas na parcela. Ao final do período de avaliação de controle também foram aferidos a altura e a massa seca de plantas nos tratamentos aplicados em PRÉ e PÓS-I, além da massa fresca, conteúdo de água e número de plantas emergidas nos tratamentos em PRÉ.

Os dados foram submetidos a análise de homogeneidade de variâncias e adequação a distribuição normal, transformados por $\operatorname{sqr}(x-1)$ quando necessário, e submetidos a análise de variância pelo teste $\mathrm{F}$ ao nível de $5 \%$ de probabilidade. Quando significativas as avaliações de controle foram analisadas por regressão não-linear em função de dias após aplicação dos tratamentos. Os dados qualitativos foram submetidos à comparação múltipla de médias pelo teste de Duncan, ao nível de $5 \%$ de probabilidade.

\section{Resultados e Discussão}

Os tratamentos aplicados em préemergência (T1-T5) variaram quanto a capacidade de inibir a germinação de plantas de feijão-de-rôla, ao nível de $5 \%$ de probabilidade (Figura 1).

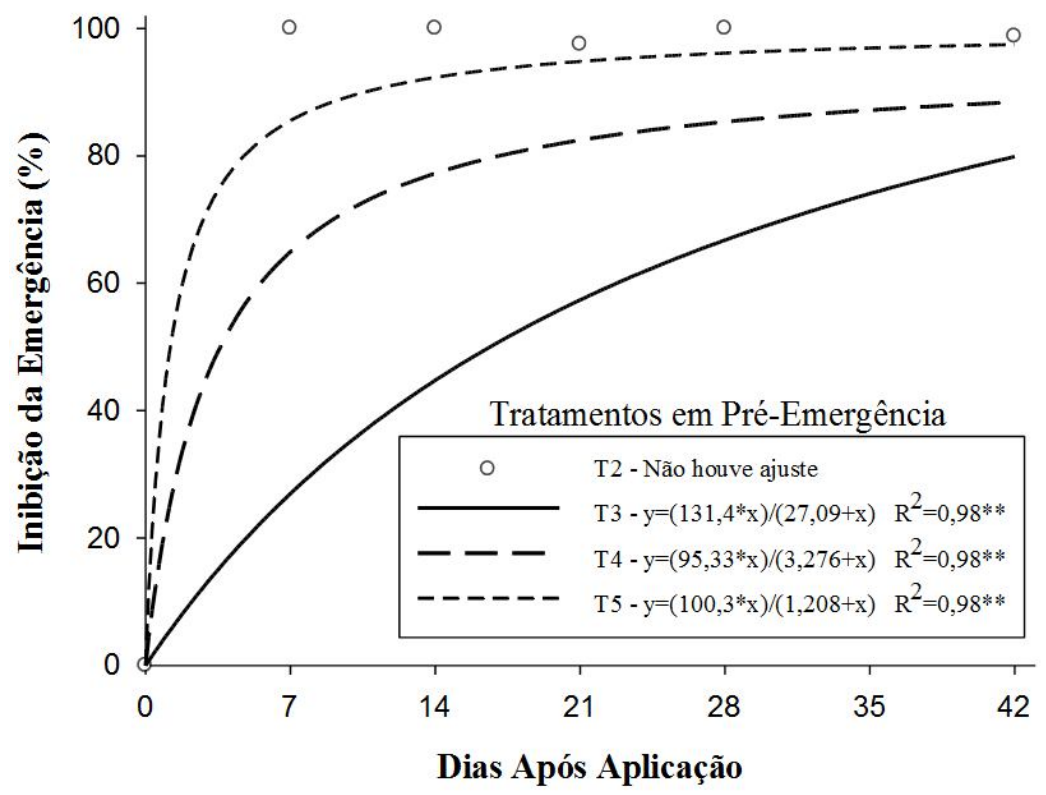

Figura 1. Inibição da emergência de plântulas de Macroptilium lathyroides em função da aplicação dos herbicidas e misturas em pré-emergência. Embrapa Agropecuária Oeste, Dourados-MS, 2011. T2 sulfentrazone (500 $\left.\mathrm{g} \mathrm{ha}^{-1}\right)$; $\mathbf{T 3}$ chlorimuron-ethyl (16,5 $\left.\mathrm{g} \mathrm{ha}^{-1}\right)$; T4 2,4-D (670 $\left.\mathrm{g} \mathrm{ha}^{-1}\right)$; $\mathbf{T 5}$ diuron (2000 $\mathrm{g}$ $\left.\mathrm{ha}^{-1}\right)$.

O sulfentrazone (500 $\mathrm{g} \mathrm{ha}^{-1}$ ) mostrou- feijão-de-rôla, mantendo nível de controle se eficiente na inibição da emergência de próximo a 100\% durante todo o período de 
avaliação (até 42 DAA). Não foi possível o ajuste de uma regressão significativa aos dados observados (Figura 1). Este herbicida é seletivo a cultura da soja somente com aplicação em pré-emergência, no sistema aplique-plante ou plante-aplique.

Após o estádio de início da emergência da soja (estádio conhecido como "cracking"), sua aplicação não é recomendada nesta cultura. Além disso, embora tenha sido eficiente para o controle de feijão-de-rôla em pré-emergência, sulfentrazone somente é utilizado em lavouras instaladas em solos pesados (alto teor de argila). A utilização deste herbicida em solos arenosos e francos não é indicada devido à toxicidade às plantas da cultura. Além disso, antes de sua aplicação na cultura da soja, deve-se observar as restrições descritas na bula do produto quanto a cultura a ser semeada em sucessão, pois pode apresentar meia-vida superior a 200 dias, e permanecer no solo em concentrações fitotóxicas a determinadas culturas, por período superior a um ano (Blanco \& Velini, 2005).

O herbicida chlorimuron-ethyl (16,5 g $\mathrm{ha}^{-1}$ ) mostrou-se menos eficiente que os demais na inibição da germinação de feijão-de-rôla (Figura 1). A inibição da germinação proporcionada pelo chlorimuron-ethyl foi cerca de 50-60\% em relação à testemunha sem aplicação (T1). Salienta-se que as avaliações de inibição de germinação foram sempre comparadas com o número de plantas presentes na testemunha, e assim observou-se evolução mais lenta na eficiência do chlorimuron-ethyl em relação aos demais tratamentos. O chlorimuron-ethyl é basicamente um herbicida utilizado em pós-emergência. No entanto, apresenta efeito residual em pré-emergência sobre algumas espécies eudicotiledôneas, como Bidens pilosa, Euphorbia heterophylla, Raphanus sativus, $R$. raphanistrum e Conyza bonariensis, conforme recomendação do fabricante e resultados de pesquisa (Procópio et al., 2006).
O 2,4-D (670 $\left.\mathrm{g} \mathrm{ha}^{-1}\right)$ foi eficiente na inibição da germinação de feijão-de-rôla, alcançando ao redor de $80 \%$ de inibição 14 DAA. Além disso, a manutenção do número de plantas emergidas nas avaliações posteriores pode indicar que este herbicida controlou eficientemente as demais plântulas nos estádios iniciais de germinação, antes que estas fossem capazes de emergir do solo. Embora este herbicida tenha sido eficiente no controle préemergente de feijão-de-rôla, salienta-se que sua aplicação à cultura da soja só pode ser feita na dessecação da área, e deve-se aguardar um período mínimo de 10-15 dias entre a aplicação e a semeadura da soja para evitar fitotoxicidade à cultura. Como o 2,4-D é eficiente no controle de $C$. bonariensis resistente ao glyphosate (Paula et al., 2011), pode ser alternativa interessante em áreas de alta infestação de buva que também apresentem ocorrência de feijãode-rôla.

O diuron é recomendado somente para as culturas de café, cana-de-açúcar, citros e algodão, sendo de ampla utilização em préemergência desta última (Oliveira Jr. et al., 2011). Dentre os tratamentos avaliados em préemergência, o diuron (2000 $\mathrm{g} \mathrm{ha}^{-1}$ ) foi o que apresentou os melhores resultados de controle (Figura 1), ao lado do sulfentrazone. Sob aplicação deste herbicida, foi observado que as plantas de feijão-de-rôla emergiram e cresceram até altura aproximada de $1,0-1,5 \mathrm{~cm}$, logo após sendo controladas pelo herbicida ao exporem suas folhas e utilizarem a radiação solar. Logo, foi possível avaliar com exatidão a eficiência de controle sob aplicação em préemergência deste herbicida, cujos níveis foram superiores a $85 \%$ a partir dos 7 DAA (Figura 1). Estes resultados também sugerem que na cultura do algodão o diuron possa inibir eficientemente a germinação de feijão-de-rôla por período estimado entre 15 e 30 dias, se as condições edafoclimáticas forem favoráveis.

Ao final do período de avaliação (42 DAA), as variáveis massa fresca (MF), massa 
seca (MS) e número de plantas (NP) por parcela, somente diferiram entre o grupo de tratamentos e a testemunha sem aplicação (Tabela 2). Para as variáveis altura (AP) e conteúdo de água (CA) das plantas foi possível a diferenciação entre tratamentos (Tabela 1). Para AP foi constatado maior valor para o tratamento sob aplicação de chlorimuron-ethyl em comparação ao 2,4-D, por exemplo, onde
NP não diferiu. Isto indica que, embora o número de plantas entre estes tratamentos seja similar, as plantas foram mais baixas sob efeito do 2,4-D, provavelmente devido ocasionar também maior retardo na germinação (Tabela 1). Os tratamentos com sulfentrazone também foram impactantes, e as poucas plantas que emergiram atingiram altura próxima de $0,5 \mathrm{~cm}$ aos
42

DAA.

Tabela 2. Massa fresca e seca, conteúdo de água, altura e número de plantas por vaso de Macroptilium lathyroides aos 28 DAA, em função dos herbicidas aplicados em pré-emergência. Embrapa Agropecuária Oeste, Dourados-MS, 2011.

\begin{tabular}{|c|c|c|c|c|c|}
\hline Tratamentos $^{1}$ & M.F. $^{2}$ & M.S. $^{3}$ & C.A. ${ }^{4}$ & A.P..$^{5}$ & N.P. ${ }^{6}$ \\
\hline T1. Testemunha & $2,35 \mathrm{a}^{7}$ & $0,36 \mathrm{a}^{7}$ & $84,68 \mathrm{a}^{7}$ & $7,70 \mathrm{a}^{7}$ & $6,50 a^{7}$ \\
\hline T2. Sulfentrazone $\left(500 \mathrm{~g} \mathrm{ha}^{-1}\right)$ & $0,00 \mathrm{~b}$ & $0,00 \mathrm{~b}$ & $* * *$ & $0,40 \mathrm{c}$ & $0,25 \mathrm{~b}$ \\
\hline T3. Chlorimuron $\left(16,5 \mathrm{~g} \mathrm{ha}^{-1}\right)$ & $0,18 \mathrm{~b}$ & $0,02 \mathrm{~b}$ & $86,64 \mathrm{a}$ & $4,27 \mathrm{~b}$ & $1,50 \mathrm{~b}$ \\
\hline T4. $2,4-\mathrm{D}\left(670 \mathrm{~g} \mathrm{ha}^{-1}\right)$ & $0,06 \mathrm{~b}$ & $0,01 \mathrm{~b}$ & $76,75 \mathrm{~b}$ & $1,18 \mathrm{c}$ & $1,25 \mathrm{~b}$ \\
\hline T5. Diuron (2000 $\mathrm{g} \mathrm{ha}^{-1}$ ) & $0,00 \mathrm{~b}$ & $0,00 \mathrm{~b}$ & $* * *$ & $0,50 \mathrm{c}$ & $0,50 \mathrm{~b}$ \\
\hline
\end{tabular}

${ }^{1}$ Descrição resumida dos tratamentos. ${ }^{2}$ Massa fresca de plantas (g parcela $\left.{ }^{-1}\right) ;{ }^{3}$ Massa seca de plantas $(\mathrm{g}$ parcela $\left.{ }^{-1}\right) ;{ }^{4}$ Conteúdo de água das plantas $(\%) ;{ }^{5}$ Altura de plantas $(\mathrm{cm}) ;{ }^{6}$ Número de plantas por parcela; ${ }^{7}$ Médias seguidas pela mesma letra, na coluna, não diferem pelo teste de Duncan a 5\% de probabilidade.

Para o cálculo do conteúdo de água das plantas foram utilizadas somente as repetições com plantas vivas, significando que parcelas com NP $=0$ não foram consideradas na análise de variância e comparação de médias. Desta forma, ao se utilizar os valores de MF e MS apresentados na Tabela 2 para o cálculo do $\mathrm{CA}$, estes serão divergentes pois para as primeiras variáveis, parcelas com $\mathrm{NP}=0$ foram consideradas. $\mathrm{O} \mathrm{CA}$ foi eficiente $\mathrm{em}$ diferenciar impactos de tratamentos com herbicidas, antes que variáveis diretamente aferidas possam apresentar os sintomas. Isto equivale a dizer que esta variável é mais sensível que MF ou MS isolados, quando utilizados na aferição do impacto de determinado tratamento herbicida (Cartwright, 1976). O conteúdo de água nas plantas tratadas com chlorimuron-ethyl em pré-emergência
(T3) foi similar a testemunha sem aplicação, enquanto o 2,4-D proporcionou conteúdo de água inferior aos anteriores. Para os tratamentos com aplicação de sulfentrazone e diuron não foi possível calcular o conteúdo de água devido a quase total ausência de plantas nas repetições (Tabela 2 ).

Os tratamentos aplicados em pósemergência inicial (T6-T11) estão dispostos na Tabela 1. A eficiência de controle de feijão-derôla com os tratamentos envolvendo glyphosate (T6-T8), isolado ou em mistura com outros princípios ativos é demonstrado na Figura 2, enquanto o efeito dos demais herbicidas aplicados em pós-emergência inicial (T9-T11) encontra-se na Figura 3. 


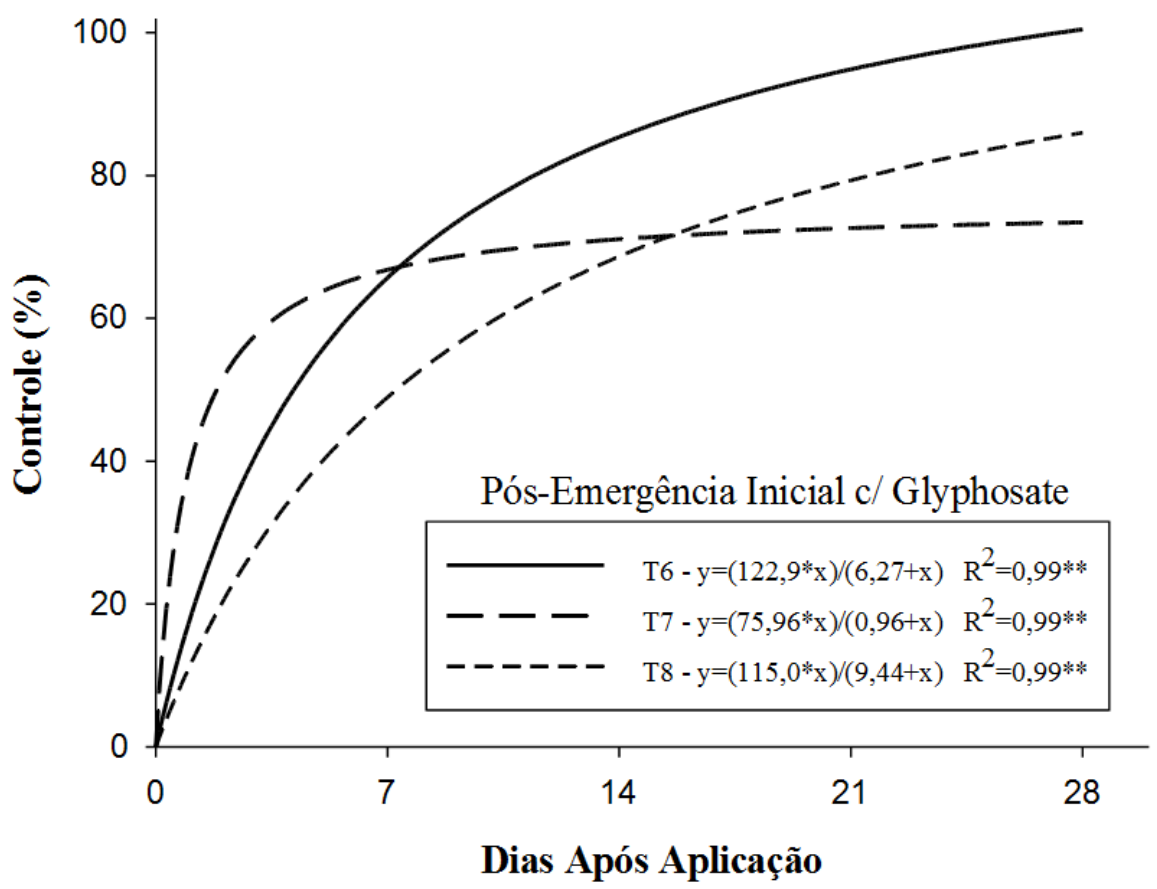

Figura 2. Controle de plantas de Macroptilium lathyroides em função dos dias após aplicação de misturas de herbicidas ao glyphosate, em pós-emergência inicial. Embrapa Agropecuária Oeste, Dourados-MS, 2011. T6 glyphosate $\left(720 \mathrm{~g} \mathrm{ha}^{-1}\right)$; T7 glyphosate + sulfentrazone $\left(720+250 \mathrm{~g} \mathrm{ha}^{-}\right.$ $\left.{ }^{1}\right)$ e $\mathbf{T 8}$ glyphosate + chlorimuron-ethyl $\left(720+16,5 \mathrm{~g} \mathrm{ha}^{-1}\right)$.

O glyphosate apresentou maior eficiência de controle de feijão-de-rôla quando aplicado isoladamente (T6) em comparação às aplicações em mistura com sulfentrazone (T7) ou chlorimuron-ethyl (T8). A mistura de glyphosate com sulfentrazone foi avaliada devido à eficiência deste último no controle de feijão-de-rôla em pré-emergência (Figura 1), e supondo que adicionado ao glyphosate na dessecação pré-semeadura da cultura, poderia fornecer efeito residual de controle da espécie. No entanto, no momento da mistura destes produtos no recipiente de preparo (sem adição de adjuvantes), foi observada incompatibilidade química que resultou na formação de grânulos e sua precipitação para o fundo do recipiente, na ausência de agitação constante. Efeito antagônico entre glyphosate e sulfentrazone já havia sido relatada por Starke \& Oliver (1998) no controle de Echinochloa crus-galli, Amaranthus palmeri, Eleusine indica e Ipomoea hederaceae var. Integriuscula. Não há menção na bula do sulfentrazone em relação a incompatibilidade ao glyphosate quando em misturas, sendo sua utilização claramente recomendada pelo fabricante na seguinte situação: (a) dessecação da área com glyphosate; (b) plantio da soja; (c) aplicação do sulfentrazone.

A mistura de glyphosate com chlorimuron-ethyl (T8), embora usada por produtores, não obteve a mesma eficiência de controle de feijão-de-rôla em comparação ao tratamento de glyphosate isolado (Figura 2). Segundo Werlang \& Silva (2002), o efeito da mistura de dois herbicidas no controle de plantas daninhas pode ser alterado em função da espécie daninha. Estes autores concluíram que a mistura de glyphosate e carfentrazoneethyl, por exemplo, demonstrou efeito aditivo no controle de Amaranthus hybridus e Bidens pilosa; efeito sinergístico no controle de 
Desmodium tortuosum; e efeito antagônico no controle de Eleusine indica. Desta forma, para o controle de feijão-de-rôla sugere-se a aplicação isolada do glyphosate para evitar prejuízos na eficiência do herbicida. Apesar de não ser claro o motivo do menor controle de feijão-de-rôla com adição de chlorimuron-ethyl ao glyphosate, alguns autores relatam a necessidade de compatibilidade entre os ingredientes da calda herbicida e a natureza da composição da cera epicuticular na superfície das folhas das plantas-alvo (Ferreira et al., 2005; Guimarães et al., 2009; Viana et al., 2010).

Outros herbicidas também foram altamente eficientes no controle de feijão-derôla em pós-emergência inicial (Figura 3). O carfentrazone-ethyl (T9), por exemplo, se mostrou altamente eficiente no controle de plantas com até $10 \mathrm{~cm}$ de altura, alcançando 93\% de controle aos 7 DAA (Figura 3). O trifloxysulfuron-sodium alcançou $98 \%$ de controle 28 DAA, exibindo evolução de sua eficiência muito lenta em função de dias após aplicação. Salienta-se que as plantas de feijãode-rôla paralisaram o crescimento quase que imediatamente após a aplicação deste herbicida, quando este foi aplicado na dose de 7,5 $\mathrm{g} \mathrm{ha}^{-1}$ e estádio de 4-6 folhas $(8-12 \mathrm{~cm}$ de altura). Como o trifloxysulfuron-sodium é utilizado na no algodão, pode constituir-se em alternativa a ser mais estudada e explorada para o controle de feijão-de-rôla em pós-emergência inicial desta cultura. $\mathrm{O}$ herbicida pyrithiobacsodium praticamente não demonstrou efeito em plantas no estádio de 4 a 6 folhas, não sendo eficiente no controle de feijão-de-rôla nestas condições (Figura 3). Este herbicida provocou manchas cloróticas nas folhas a partir dos 14 DAA, que não evoluíram resultando em $20 \%$ de controle aos 28 DAA.

A massa seca das plantas de feijão-derôla (Tabela 3) foi afetada de maneira similar por todos os tratamentos herbicidas, com exceção do pyrithiobac-sodium que apresentou massa seca de plantas aos 28 DAA similar a testemunha sem aplicação. A altura de plantas foi mais afetada pelo glyphosate aplicado isoladamente em relação aos tratamentos com a mistura de glyphosate + chlorimuron-ethyl e pyrithiobac-sodium, mas não diferiu de glyphosate+sulfentrazone, carfentrazone e trifloxysulfuron-sodium e da testemunha sem aplicação (Tabela 3). O número de plantas vivas de feijão-de-rôla por parcela só diferiu da testemunha sem aplicação e do tratamento com pyrithiobac-sodium, quando o glyphosate foi utilizado isoladamente (Tabela 3). 


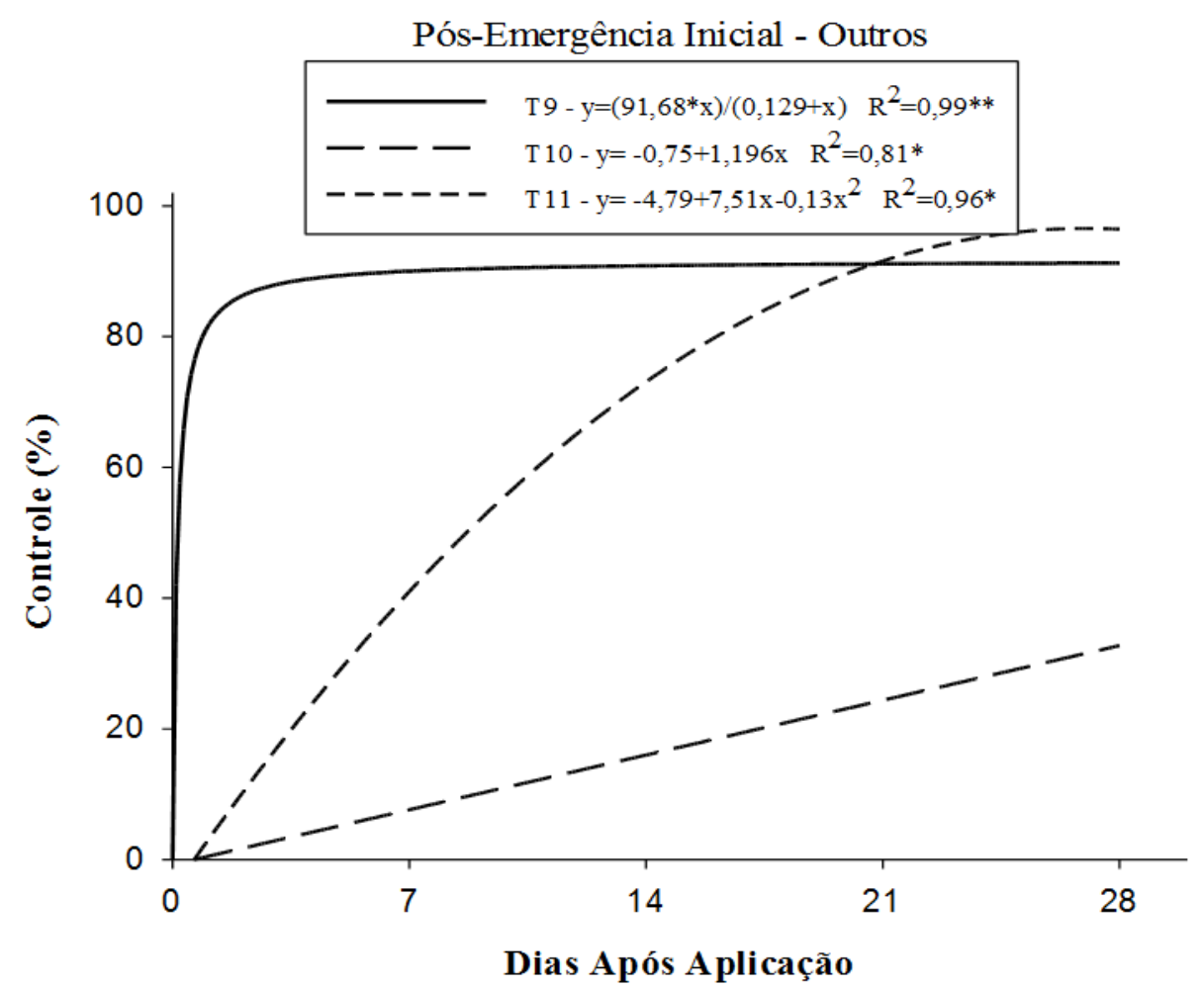

Figura 3. Controle de plantas de Macroptilium lathyroides em função dos dias após aplicação de herbicidas e misturas, em pós-emergência inicial. Embrapa Agropecuária Oeste, Dourados-MS, 2011. T9 carfentrazone-ethyl $\left(12 \mathrm{~g} \mathrm{ha}^{-1}\right)$; $\mathbf{T 1 0}$ pyrithiobac-sodium $\left(42 \mathrm{~g} \mathrm{ha}^{-1}\right)$; T11 trifloxysulfuron-sodium $\left(7,5 \mathrm{~g} \mathrm{ha}^{-1}\right)$.

Tabela 3. Massa seca, altura e número de plantas de Macroptilium lathyroides aos 28 DAA, em função dos herbicidas e misturas aplicadas em pós-emergência inicial. Embrapa Agropecuária Oeste, Dourados-MS, 2011

\begin{tabular}{lccc}
\hline Tratamento $^{1}$ & Massa Seca $\left(\mathrm{g} \mathrm{pl}^{-1}\right)$ & Altura $(\mathrm{cm})$ & $\mathrm{N}^{\circ}$ Plantas \\
\hline T1. Testemunha & $3,27 \mathrm{a}^{2}$ & $16,23 \mathrm{a}^{2}$ & $3,71 \mathrm{a}^{2}$ \\
T6. Glyphosate $\left(720 \mathrm{~g} \mathrm{ha}^{-1}\right)$ & $0,06 \mathrm{~b}$ & $1,75 \mathrm{~b}$ & $0,25 \mathrm{~b}$ \\
T7. Glyphosate + & $0,60 \mathrm{~b}$ & $8,00 \mathrm{ab}$ & $2,50 \mathrm{ab}$ \\
$\quad \begin{array}{l}\text { Sulfentrazone }\left(720+250 \mathrm{~g} \mathrm{ha}^{-1}\right) \\
\text { T8. Glyphosate + }\end{array}$ & $0,33 \mathrm{~b}$ & $14,00 \mathrm{a}$ & $1,75 \mathrm{ab}$ \\
$\quad$ Chlorimuron $\left(720+16,5 \mathrm{~g} \mathrm{ha}^{-1}\right)$ & & & \\
T9. Carfentrazone $\left(12 \mathrm{~g} \mathrm{ha}^{-1}\right)$ & $0,08 \mathrm{~b}$ & $10,25 \mathrm{ab}$ & $2,50 \mathrm{ab}$ \\
T10. Pyrithiobac $\left(42 \mathrm{~g} \mathrm{ha}^{-1}\right)$ & $2,44 \mathrm{a}$ & $14,25 \mathrm{a}$ & $3,50 \mathrm{a}$ \\
T11. Trifloxysulfuron $\left(7,5 \mathrm{~g} \mathrm{ha}^{-1}\right)$ & $0,28 \mathrm{~b}$ & $5,70 \mathrm{ab}$ & $1,25 \mathrm{ab}$ \\
\hline
\end{tabular}

${ }^{1}$ Descrição resumida dos tratamentos. Para descrição completa, favor ver Tabela $1 ;{ }^{2}$ Médias seguidas pela mesma letra, na coluna, não diferem pelo teste de Duncan a $5 \%$ de probabilidade. 
Os tratamentos em pós-emergência tardia foram aplicados sobre plantas que estavam no estádio de abertura do primeiro botão floral, entre 20 e $30 \mathrm{~cm}$ de altura. O carfentrazone-ethyl (T12) apresentou controle máximo desta espécie de $30 \%$ aos 7 DAA, com níveis de decrescentes a partir desta avaliação
(Figura 4). Ao que parece, a eficiência deste herbicida sobre feijão-de-rôla é dependente do estádio de desenvolvimento, pois a mesma dose em estádio inicial de desenvolvimento da planta daninha (T9 - Figura 3) proporcionou níveis de controle ao redor de $90 \%$, a partir da avaliação dos
DAA.

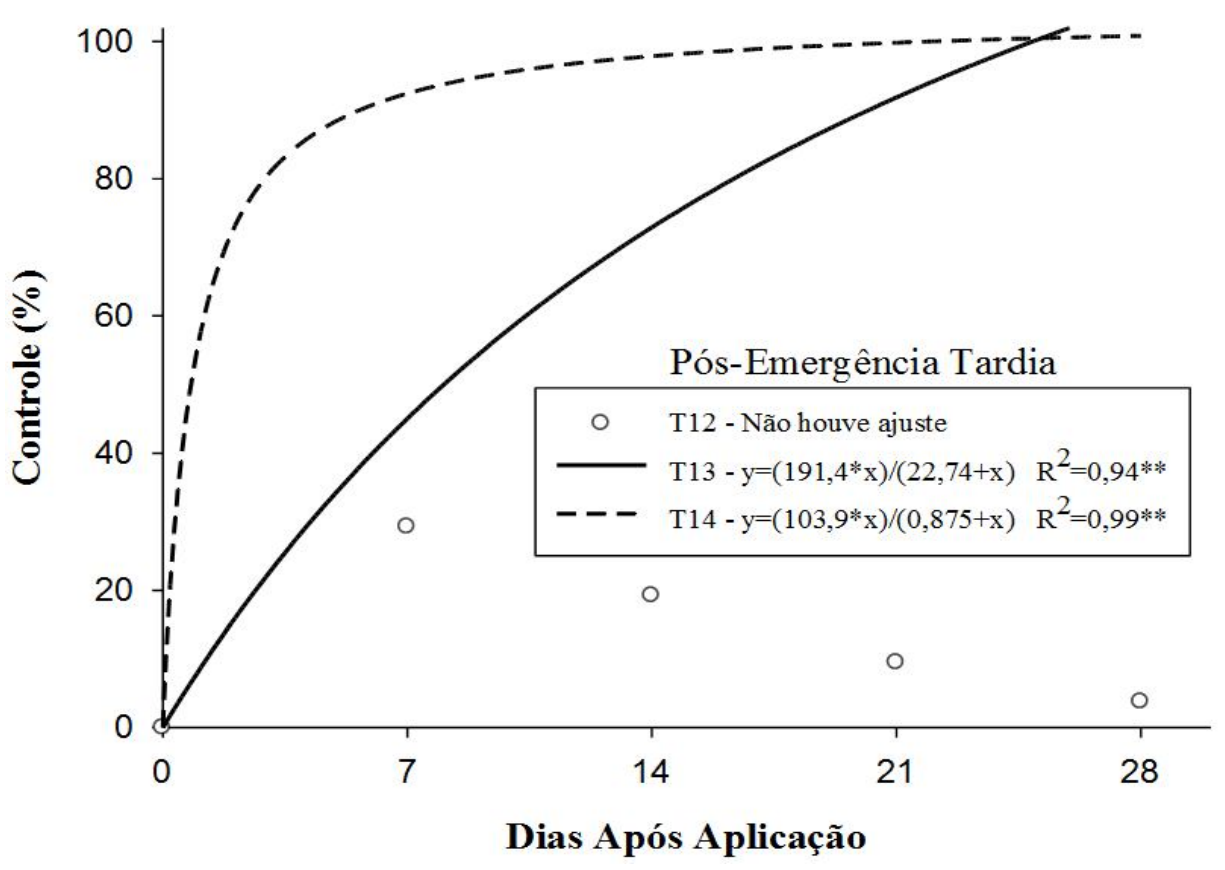

Figura 4. Controle de plantas de Macroptilium lathyroides em função dos dias após aplicação de herbicidas, em pós-emergência no estádio de início do florescimento. Embrapa Agropecuária Oeste, Dourados-MS, 2011. T12 carfentrazone-ethyl (12 $\left.\mathrm{g} \mathrm{ha}^{-1}\right)$; T13 glyphosate (1080 $\left.\mathrm{g} \mathrm{ha}^{-1}\right)$; T14 amonio-glufosinate $\left(500 \mathrm{~g} \mathrm{ha}^{-1}\right)$.

O glyphosate aplicado isoladamente sobre feijão-de-rôla em estádio de floração, na dose de 1080 g e.a. ha ${ }^{-1}$, resultou em $98 \%$ de controle aos 28 DAA (Figura 4). Ressalta-se ainda que dois dias após a aplicação foram observadas manchas de raspagens nas folhas de feijão-de-rôla semelhantes às causadas por insetos ou pequenos invertebrados fitófagos. Embora não tenha sido possível concluir se estas manchas apareceram em função da aplicação do herbicida, não foram encontrados, no experimento ou nas imediações, insetos ou outros organismos que pudessem ser responsabilizados por estas manchas. Estas manchas foram observadas somente nas plantas tratadas com glyphosate e aos 1 DAA de amonio-glufosinate.

A aplicação do amonio-glufosinate na dose de $500 \mathrm{~g} \mathrm{ha}^{-1}$ também resultou em elevados índices de controle, com $85 \%$ de eficiência aos 7 DAA, e 96\% aos 28 DAA (Figura 4), provando que este herbicida também pode se constituir como alternativa 
para o controle desta espécie na dessecação de plantas adultas.

Nos estudos em casa-de-vegetação as plantas de Macroptilium lathyroides mostraram-se sensíveis a uma ampla gama de princípios ativos, em função do estádio de desenvolvimento da forrageira. Supõe-se que as queixas de falhas de controle desta espécie por alguns produtores, possam ser atribuídas a alguma prática que contribua para a seleção desta espécie na área, em detrimento das demais. Outro fator de insucesso pode estar relacionado a problemas de tecnologia de aplicação.

\section{Conclusões}

O herbicida glyphosate foi eficiente no controle de Macroptilium lathyroides, e falhas de controle devem-se a probloemas na tecnologia de aplicação.

Salienta-se ainda, que a adição de outros herbicidas ao glyphosate, de maneira geral, reduziu sua eficiência no controle de feijão-de-rôla, embora se desconheça a causa exata deste comportamento dos tratamentos em mistura observado neste estudo.

Novos estudos em condição de campo são necessários, uma vez que condições edafoclimáticas adversas pode promover alteração significativa da eficiência de alguns dos tratamentos estudados.

\section{Referências}

ALMEIDA, L.D. et al. Efeitos de métodos de escarificação na germinação de sementes de cinco leguminosas forrageiras. Bragantia, v.38, n.9, p.83-96, 1979.

BASILE, A. G. et al. Controle químico de feijão-de-rôla (Macroptilium lathyroides) com glyphosate. In: SIMPÓSIO INTERNACIONAL SOBRE GLYPHOSATE,
1., 2007, Botucatu. Anais... Botucatu: FCA, UNESP, 2007. 1 CD-ROM.

BLANCO, F.M.G.; VELINI, E.D. Persistência do herbicida sulfentrazone em solo cultivado com soja e seu efeito em culturas sucedâneas. Planta Daninha, v.23, n.4, p.693-700, 2005.

CARTWRIGHT, P.M. General growth responses of plants. In: AUDUS, L. J. Herbicides, physiology, biochemistry, ecology. London: Academic Press, 1976. v.2, p.55-82.

DELGADO-SALINAS, A.; LEWIS, G. P. A. new species of Macroptilium (Benth.) Urb. (Leguminosae: Papilionoideae: Phaseolinae) from North-Eastern Brazil. Kew Bulletin, v.63, n.1, p.151-154, 2008.

EUROPEAN WEED RESEARCH COUNCIL. Report of $3^{\text {rd }}$ and $4^{\text {th }}$ meetings of EWRC: cites of methods in weed research. Weed Research, V.4, n.1, p.88, 1964.

FERREIRA, E. A. et al. Composição química da cera epicuticular e caracterização da superfície foliar em genótipos de cana-deaçúcar. Planta Daninha, v.23, n.4, p.611-619, 2005.

FERREIRA, O. G. L. et al. Efeito do corte da parte aérea e de épocas de colheita sobre o rendimento e qualidade das sementes de feijão-dos-arrozais. Revista Brasileira de Agrociência, v.10, n.2, p.175-178, 2004.

GUERRA, J.G.M. et al. Desempenho de leguminosas tropicais perenes como plantas de cobertura do solo. Seropédica: Embrapa Agrobiologia, 2007. 22 p. (Embrapa Agrobiologia. Boletim de pesquisa e desenvolvimento, 20).

GUIMARAES, A.A. et al. Composição química da cera epicuticular de biótipos de azevém resistente e suscetível ao glyphosate. Planta Daninha, v.27, n.1, p.149-154, 2009.

MONKS, P.L. et al. Produção e qualidade de sementes de Macroptilium lathyroides (L.). 
Urb. sob diferentes espaçamentos e épocas de colheita. Pesquisa Agropecuária Tropical, v.36, n.2, p.107-112, 2006.

OLIVEIRA JR, R.S et al. Aplicações isoladas ou associadas de diuron, oxyfluorfen e prometryne para o controle de Euphorbia heterophylla. Planta Daninha, v.29, n.3, p.635-643, 2011.

PAULA, J. M. et al. Manejo de Conyza bonariensis resistente ao herbicida glyphosate. Planta Daninha, v.29, n.1, p.217-227, 2011.

PROCOPIO, S.O. et al. Eficácia de imazethapyr e chlorimuron-ethyl em aplicações de pré-semeadura da cultura da soja. Planta Daninha, v.24, n.3, p.467-473, 2006.

SANTOS, F.J. et al. Controle químico de plantas daninhas na cultura do arroz irrigado no Estado do Ceará. Planta Daninha, v.18, n.1, p.29-37, 2000.
SNAK, C. Phaseolinae Benth. (Leguminosae, Papilionoideae, Phaseoleae) no Estado do Paraná, Brasil. 2011. 89 f. Dissertação (Mestrado em Botânica) - Setor de Ciências Biológicas, Universidade Federal do Paraná, Curitiba.

STARKE, R. J.; OLIVER, L. R. Interaction of glyphosate with chlorimuron, fomesafen, imazethapyr, and sulfentrazone. Weed Science, v. 46, n.6, p. 652-660, 1998.

VASCONCELOS, W. A. et al. Germinação de sementes e desenvolvimento de plântulas de figo de pombo (Macroptilium lathyroides). Revista Trópica, v.5, n.1, p.3-11, 2011.

VIANA, R.G. et al. Quantificação e composição química de cera epicuticular de folhas de eucalipto. Planta Daninha, v.28, n.4, p.753-758, 2010.

WERLANG, R.C.; SILVA, A.A. Interação de glyphosate com carfentrazone-ethyl. Planta Daninha, v.20, n.1, p.93-102, 2002. 